\title{
Microbial flora of the vagina and cervix
}

\author{
CATHERINE M. CORBISHLEY
}

From the University Department of Bacteriology, Bristol Royal Infirmary, Bristol BS2 $8 H W$, England

SUMMARY The microbial flora of the vagina and cervix was assessed qualitatively and semiquantitatively in 40 women attending an intrauterine contraceptive device clinic. Both sites harboured many types of microorganism, the mean number of microbial types isolated being five from the vagina and four from the cervix. Typical lactobacilli were detected in $61 \%$ of vaginal and in $53 \%$ of cervical specimens; faecal bacteria, including anaerobes, were even more frequently found at both sites. No differences in the microbial populations at either the vagina or the cervix were detected after fitting of the devices, in the different weeks of the menstrual cycle, or with various previously used contraceptive methods.

The received impression of the microbial flora of the female lower genital tract is of predominant lactobacilli with occasional colonisation by skin and faecal organisms (Wilson and Miles, 1975). Recent papers have challenged this view by showing a diverse collection of organisms at this site, but there is much still to be elucidated about the microbial ecology of this region and the factors affecting it.

The present investigation of 40 women attending an intrauterine contraceptive device (IUCD) clinic was undertaken to assess the vaginal and cervical flora in this sexually active group and to determine the effect of various influences-the fitting of the device itself, and factors such as the stage of the menstrual cycle, and previous contraceptive practice.

\section{Material and methods}

\section{PATIENTS}

Of the 40 patients who attended for IUCD fitting, 30 returned for the first follow-up appointment, usually four weeks later, so that 70 sets of vaginal and cervical swabs were taken for culture. The women were asked about previous contraceptive practice and drug history, and relevant clinical details were noted. The age range of the patients was 19 to 40 years, the mean age being $25 \cdot 5$ years.

\section{DEVICES}

Twenty-one patients of the 30 who returned for follow-up had the copper 7 (Gravigard) device fitted,

Received for publication 7 February 1977 and the remaining nine had plastic devices, mainly Lippes' loops.

SPECIMENS

High vaginal and endocervical swabs were taken while the cervix was in view through a speculum. Care was taken to avoid contamination of cervical swabs by vaginal secretions. The dry swabs were immediately placed in Stuart's transport medium.

\section{CULTURE}

The swabs were each inoculated on to five primary culture media within two hours of collection. The media used were as follows: (1) $5 \%$ horse blood agar; (2) MacConkey's bile salt agar; (3) Sabouraud's glucose-peptone agar; (4) $0.0075 \%$ neomycin blood agar; and (5) tomato juice agar (Oxoid).

Plates 1, 2, and 3 were incubated aerobically and plates 4 and 5 were incubated anaerobically using the Gas-Pak system. All the plates were examined after 36 hours' incubation at $37^{\circ} \mathrm{C}$.

\section{ASSESSMENT}

All colonial types on each medium were investigated further by microscopy and biochemical and physiological tests, and divided into genera and species by routine laboratory methods (Cruickshank et al., $1975)$ to give the categories listed in Tables 1 and 2. Organisms which appeared as more than 20 colonies on the plate with the heaviest growth of that organism were defined as isolations in abundance.

Candida albicans was identified by its ability to produce germ-tubes when incubated in serum for 2 
Table 1 Organisms isolated from genital tract

\begin{tabular}{|c|c|c|c|c|}
\hline \multirow[t]{2}{*}{ Microorganism } & \multicolumn{2}{|c|}{ Vaginal swab } & \multicolumn{2}{|c|}{ Cervical swab } \\
\hline & $\mathrm{No} / 70$ & $\%$ & $\mathrm{No} / 70$ & $\%$ \\
\hline Acid tolerant bacteria & 62 & 89 & 56 & 80 \\
\hline (Typical lactobacilli) & (43) & (61) & (37) & (53) \\
\hline Staphylococcus aureus (coagulase + ) & 12 & 17 & 12 & 17 \\
\hline Staphylococcus sp. (coagulase -) & 62 & 89 & 51 & 73 \\
\hline Faecal streptococci & 25 & 36 & 20 & 29 \\
\hline Anaerobic streptococci & 38 & 54 & 30 & 43 \\
\hline Other streptococci & 7 & 10 & 7 & 10 \\
\hline Diphtheroids & 48 & 69 & 45 & 64 \\
\hline Bacillus sp. & 5 & 7 & 5 & 7 \\
\hline Clostridium welchii & 1 & 1 & 1 & 1 \\
\hline 'Haemophilus vaginalis' & 14 & 20 & 13 & 19 \\
\hline Bacteroides sp. & 17 & 24 & 14 & 20 \\
\hline Coliforms (lactose-fermenting) & 22 & 31 & 19 & 27 \\
\hline Proteus sp. & 2 & 3 & 1 & 1 \\
\hline Other Enterobacteriaceae & $\sqrt{12}$ & 17 & 6 & 9 \\
\hline Oxidase-positive Gram-neg. bacilli & 5 & 7 & 3 & 4 \\
\hline Parvobacteria & 2 & 3 & 2 & 3 \\
\hline Candida albicans & 10 & 14 & 6 & 9 \\
\hline
\end{tabular}

Table 2 Organisms isolated in abundance

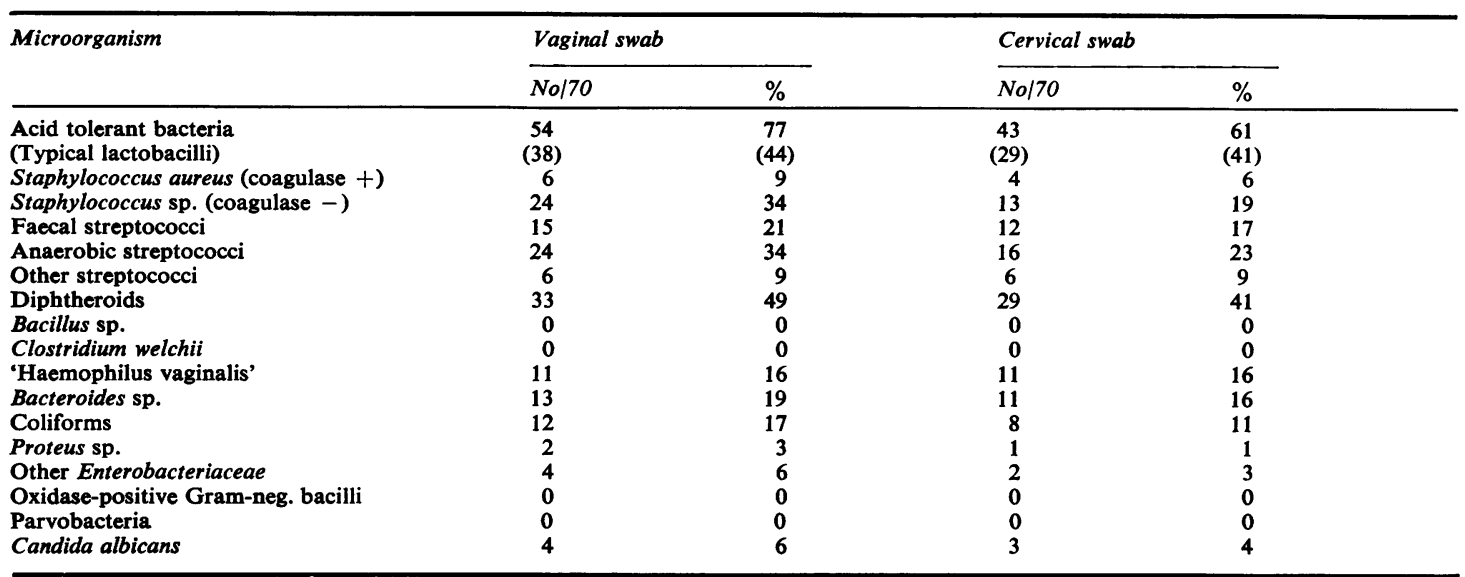

hours at $37^{\circ} \mathrm{C}$. Gram-negative organisms which showed little or no growth on MacConkey's agar, but grew on other media, were called parvobacteria. Streptococci which grew on MacConkey's agar were defined as faecal streptococci. Lactobacilli were identified by their morphology when Gram filmed and their ability to grow on tomato juice agar. Other organisms which grew on tomato juice agar, which did not fit into any other category, were called acid tolerant bacteria. The organisms called 'Haemophilus vaginalis' grew as pinpoint $\alpha$-haemolytic or non-haemolytic colonies on aerobic blood agar and neomycin blood agar, and appeared as Gram variable short rods when Gram filmed. It is believed that this organism, which has growth characteristics quite distinct from diphtheroids, is the same organism as that defined as Haemophilus vaginalis by Gardner and Dukes (1955) or Corynebacterium vaginale by Zinnemann and Turner (1962).
The $\chi^{2}$ test was used as a test of statistical significance when comparing results.

\section{Results}

VAGINAL AND CERVICAL FLORA

The Figure shows the number of different types of organism isolated from each swab, and also the number of times these types were isolated in abundance. The mean number of types of organism isolated from a vaginal swab was five, whereas for a cervical swab it was four. The mean number of types isolated in abundance was three for vaginal swabs, and two for cervical swabs. Table 1 shows the numbers of swabs which yielded each type of organism, and Table 2 the numbers of swabs producing each type in abundance.

Thus, in general, there were less microbial types isolated from the cervix than from the vagina. When 


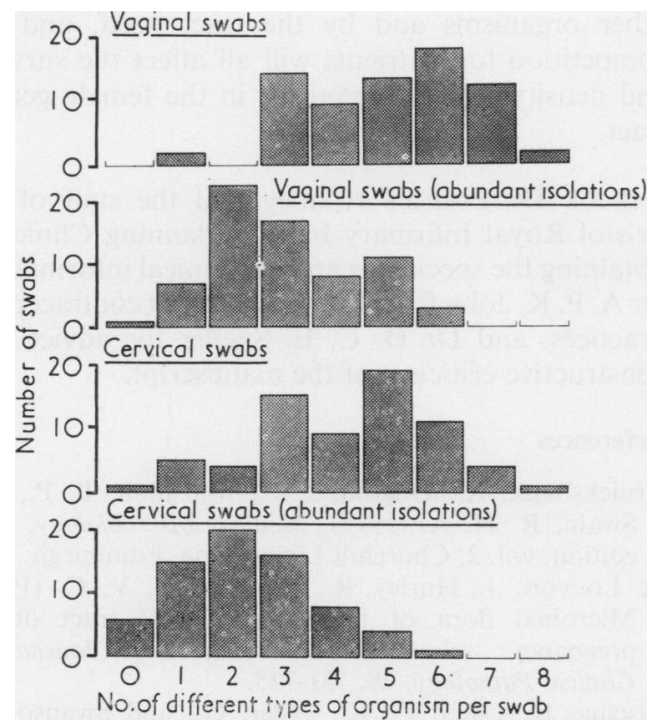

Figure Numbers of different types of microorganism isolated from cervical and vaginal swabs

the same organism was isolated from both sites it was usually found in lower numbers at the cervix. Acid tolerant bacteria were grown from nearly $90 \%$ of vaginal swabs, but only $60 \%$ of these were typical lactobacilli. The remaining one-third of the isolates of acid tolerant bacteria were Gram-positive cocci, probably $\alpha$-haemolytic streptococci.

Anaerobic streptococci and diphtheroids were found in well over half the vaginal cultures. Almost $50 \%$ of the swabs produced diphtheroids in large numbers. One or more type of organism of faecal origin (of the groups faecal streptococci, Clostridium welchii, bacteroides, coliforms and other Enterobacteriaceae) were grown from $69 \%$ of vaginal swabs and from $67 \%$ of cervical swabs.

\section{EFFECT OF IUCD INSERTION}

A comparison of the swabs taken at IUCD fitting and at the first follow-up appointment of those 30 patients who returned to the clinic showed no significant differences in the patterns of flora between the two sets of swabs, the full range of bacteria being cultured in both cases. There was no difference between the 21 patients who had copper devices and the nine who had plastic devices fitted.

\section{OTHER CONTRACEPTIVE METHODS}

At the first visit to the clinic most of the women were using alternative methods of contraception, the commonest method being an oral contraceptive pill (17 patients). Fifteen patients used either no method or a physical barrier method, and four used spermi- cidal foams or creams. The remaining four patients were having IUCDs fitted post partum. There were no significant differences of flora in these groups, but the numbers of specimens were small.

THE MENSTRUAL CYCLE

It is the practice of the Family Planning Clinic to insert IUCDs in the first week of the menstrual cycle if possible. Of the 70 pairs of swabs, 40 were taken in the first week of the cycle, 10 in the second week, and 13 in the last two weeks, the remaining 7 being taken from women with irregular cycles or post partum. There was no noticeable variation in the frequency of any organism, or change in the pattern of flora, relating to different times of the menstrual cycle.

DISCHARGE AND IRRITATION

Eleven patients had vaginal discharge or irritation, or both, but in only one case was this related to the presence of a known vaginal pathogen, in this instance Candida albicans. The presence of large numbers of Staphylococcus aureus, 'Haemophilus vaginalis' or coliforms was not correlated with vaginal pathology. The protozoon Trichomonas vaginalis was not looked for.

\section{Discussion}

The use of the intrauterine contraceptive device reflects social attitudes and medical enthusiasms as as well the sexual and obstetric histories of the women themselves. IUCDs may be fitted post partum and are often a second choice for contraception where oral contraceptives are unacceptable. Some details of 1014 patients fitted with IUCDs are given by Hull and Henderson (1975).

In the present series of patients, although few culture media were used, three or more microbial types were obtained from $97 \%$ of the vaginal swabs. Recently reported studies show that this is true of other groups of women of child-bearing age (Morris and Morris, 1967; Keith et al., 1972; Neary et al., 1973; de Louvois et al., 1975). It has been postulated (Keith et al., 1972) that the vagina and cervix, with different embryological origins, epithelia, and secretions, might have different microbial populations; but in this first comparative investigation the same pattern, including bacteria of faecal origin, was found at the two sites, $70 \%$ of cervical swabs yielding three or more microbial types.

Lactobacilli have been thought to be overwhelmingly preponderant in the vagina. In this investigation they were found in $61 \%$ of vaginal swabs and in $53 \%$ of cervical swabs. Other surveys show incidences of lactobacilli varying between $50 \%$ and $80 \%$ (Morris and Morris, 1967, 49.1\%; Keith et al.,1972, 60\%; de Louvois et al., 1975, 81.8\%; Ohm 
and Galask, $1975,75 \%$ ). Sugars may be fermented with the production of acid by many types of bacterium present in the vagina, for example, $\alpha$ haemolytic streptococci and vaginal corynebacteria, which may contribute to the low $\mathrm{pH}$ of the vagina (Laughton, 1950). The high incidence of diphtheroids $(61 \%)$, and also their incidence in abundance $(41 \%)$, indicate they are quite constant inhabitants of the vagina.

Anaerobic bacteria were isolated with a frequency comparable with the results of other investigations specially designed to recover such bacteria (Gorbach et al., 1973; Ohm and Galask, 1975). Faecal streptococci and coliforms were common, but $\mathrm{Cl}$. welchii, Proteus, and other Enterobacteriaceae were rare. The high incidence of faecal organisms is not surprising, considering the close proximity of the anus to the female genital tract.

Coagulase-negative staphylococci were frequently found at the cervix $(79 \%)$ and in the vagina $(89 \%)$, although in only one-quarter of cases were they found in large numbers. Staph. aureus was isolated from $17 \%$ of swabs. The origin of all the staphylococci is probably the flora of the skin.

No significant change in the incidence of any microorganism in the menstrual cycle was found in this investigation. Such differences have been reported for Escherichia coli $(8.6 \%$ in the first half of the cycle and $4.3 \%$ in the second half) by Morris and Morris (1967); and for bacteroides (17\% in the first half and $2.5 \%$ in the second) by Neary et al. (1973). In the present series the isolation rates for these bacteria were higher-coliforms $31 \%$, bacteroides $24 \%$.

Most of the IUCDs fitted were of copper, and low concentrations of copper ions have been shown to be toxic in vitro to Neisseria gonorrhoeae (Fiscina et al., 1973) although not in vivo (Spellacy et al., 1974). In the present investigation no effect was noted against any of the organisms studied.

Only one patient had vaginitis attributable to a particular pathogen, in this case $C$. albicans. Nine patients harboured this yeast in the absence of any clinical symptoms; and no type of organism was consistently associated with genital pathology. There are more factors involved in the pathogenicity of these organisms than their ability to survive and multiply at a site.

The wide variety of organisms, some of which are almost invariably present, indicate that the human vagina and cervix should be regarded as bearing not a pure resident flora of lactobacilli with occasional transient colonisation by other bacteria, but a complex flora of interacting and competing microorganisms. The conditions of low $\mathrm{pH}$ and oxygen tension, the production of inhibitory substances by other organisms and by the tract itself, and the competition for nutrients will all affect the survival and density of any organisms in the female genital tract.

I thank Dr Frances Hindley and the staff of the Bristol Royal Infirmary Family Planning Clinic for obtaining the specimens and the clinical information, Dr A.P. K. John for information about contraceptive practices, and Dr D. C. E. Speller for advice and constructive criticism of the manuscript.

\section{References}

Cruickshank, R., Duguid, J. P., Marmion, B. P., and Swain, R. H. A. (1975). Medical Microbiology, 12th edition, vol. 2, Churchill Livingstone, Edinburgh.

de Louvois, J., Hurley, R., and Stanley, V. C. (1975). Microbial flora of the lower genital tract during pregnancy: relationship to morbidity. Journal of Clinical Pathology, 28, 731-735.

Fiscina, B., Oster, G. K., Oster, G., and Swanson, I. (1973). Gonococcicidal action of copper in vitro. American Journal of Obstetrics and Gynecology, 116, 86-90.

Gardner, H. L. and Dukes, C. D. (1955). Haemophilus vaginalis vaginitis: a newly defined specific infection previously classified as 'nonspecific' vaginitis. American Journal of Obstetrics and Gynecology, 69, 962-976.

Gorbach, S. L., Menda, K. B., Thadepalli, H., and Keith, L. (1973). Anaerobic microflora of the cervix in healthy women. American Journal of Obstetrics and Gyneco$\log y, 117,1053-1055$.

Hull, F. M. and Henderson, J. M. (1975). Intra-uterine contraception in general practice. Journal of the Royal College of General Practitioners, 25, 924-931.

Keith, L., England, D., Bartizal, F., Brown, E., and Fields, C. (1972). Microbial flora of the external os of the premenopausal cervix. British Journal of Venereal Diseases, 48, 51-56.

Laughton, N. (1950). Vaginal corynebacteria. Journal of Hygiene, 48, 346-356.

Morris, C. A. and Morris, D. F. (1967). 'Normal' vaginal microbiology of women of childbearing age in relation to the use of oral contraceptives and vaginal tampons. Journal of Clinical Pathology, 20, 636-640.

Neary, M. P., Allen, J., Okubadejo, O. A., and Payne, D. J. H. (1973). Preoperative vaginal bacteria and postoperative infections in gynaecological patients. Lancet, 2, 1291-1294.

Ohm, M. J. and Galask, R. P. (1975). Bacterial flora of the cervix from 100 prehysterectomy patients. American Journal of Obstetrics and Gynecology, 122, 683-687.

Spellacy, W. N., Hiser, B. J., and Birk, S. A. (1974). The effect of copper intrauterine devices on endocervical gonococcal cultures. Fertility and Sterility, 25, 772-773.

Wilson, G. S. and Miles, A. (1975). Topley and Wilson's Principles of Bacteriology, Virology and Immunity, 6th edition, pp. 2617-2618. Arnold, London.

Zinnemann, K. and Turner, G. C. (1962). Taxonomy of Haemophilus vaginalis. Nature, 195, 203. 